\title{
Devlet Orman İşletmelerinin Etkinlik Düzeylerinin Ölçülmesi: Doğu Karadeniz Bölgesi Örneği
}

\author{
Mahmut M. BAYRAMOĞLU*, Devlet TOKSOY \\ Karadeniz Teknik Üniversitesi Orman Fakültesi, 61040, Trabzon/Türkiye \\ "Sorumlu yazar: mahmud@ktu.edu.tr
}

Geliş Tarihi: 01.08.2016

\begin{abstract}
Özet
Dünya'da 19. yüzyılda gerçekleşen sanayi devrimi, gelişen piyasa ekonomisi ve teknolojiyle birlikte özellikle Avrupa'da nüfus ve hayat standartlarında önemli değişiklikler meydana getirmiştir. Bu değişiklikler beraberinde doğal kaynaklara ve özellikle ormanlara olan talebi daha da arttırmıştır. Oluşan bu talebin sürdürülebilir bir şekilde karşılanması ancak sahip olunan doğal kaynakların etkin bir şekilde yönetilmesiyle mümkün olmaktadır. Bu kapsamda Doğu Karadeniz Bölgesi'nde faaliyet gösteren 21 Devlet Orman İşletmesinin (DOİ) etkinlik düzeyleri, ormanların ve dolayısıyla DOİ'lerin ekonomik, ekolojik ve sosyal fonksiyonları göz önünde bulundurularak, 4 farklı durum için belirlenmiştir. Veri Zarflama Analizi (VZA) sonuçlarına göre I. durumda 4, II. durumda 5, III. durumda 4 ve IV. durumda ise 6 DOİ etkin çıkmıştır. Devlet Orman İşletmelerinin varlıklarını devam ettirebilmeleri ve sahip oldukları kaynakları daha etkin kullanabilmeleri için özellikle kuruluşlarında, ekonomik ölçütlere dayanmayan ve ekonomik analizler yapılmadan siyasi kararların etkisinde kalınmamalıdır. Bu durumu ortadan kaldırmak için DOİ'lerde personel politikaları ve maliyetlendirme konuları gözden geçirilmelidir. Maliyet minimizasyonu çalışmalarıyla birlikte üretim ve satış programlarının da bu amaç doğrultusunda planlanması gerekmektedir.
\end{abstract}

Anahtar Kelimeler: Etkinlik, Veri Zarflama Analizi, Devlet Orman İşletmesi, Doğu Karadeniz Bölgesi Evaluation of Efficiency of State Forest Enterprises (SFE): Sample of Eastern Black Sea Region

Abstract

In 19th century industrial revolution had important impact on living standards and population in Europe with market economy and developing technologies. These developments increased the demand on natural resources and forests. In order to meet with these increasing demands, natural resources must be management efficiently. Efficiency of 21 State Forest Enterprise (SFE) in Eastern Black Sea Region was evaluated for four different cases in relation to economic, ecologic and social functions. According to Data Envelopment Analysis (DEA) in first (I) case had 4 efficient SFEs, second (II) case had 5, third (III) case 4, and forth (IV) case had 6 efficient SFEs. There should be no political influence on state forest enterprises, especially during their establishment stage without any economic analyses or economic measures, for them to have sustainability and efficiency. Personnel policies and costing of SFE's require urgent attention. Cost minimization along with production and sale programs should be planned accordingly.

Keywords: Efficiency, Data Envelopment Analysis, State Forest Enterprise, Eastern Black Sea Region

\section{Giriş}

Dünya nüfusunun ve tüketiminin artmas1, sanayileşmenin hızlanması, artan ihtiyaçların karşılanması için daha fazla miktarda gıdaya ve hammaddeye ihtiyaç duyulması, bu hammadde ihtiyacının büyük çoğunluğunun yenilenebilir olmayan kaynaklardan karşılanıyor olması, neticede dünya üzerindeki miktarı sınırlı olan bu kaynakların azalmasına, hatta tükenmesine yol açmaktadır (Ateş ve Ateş, 2015). Bununla birlikte üretilen temel mal ve hizmetlerin miktar ve kalitelerinin bu artışı karşılayamaması doğal kaynaklara ve özellikle ormanlara olan talebi ve beklentileri de arttırmıştır (Güngör ve Ayhan, 2016). Yenilenebilir bir doğal kaynak olan orman kaynaklarına yönelik toplumun talepleri nitel ve nicel olarak değişmiş ve odun hammaddesi üretimi dişında kalan, daha çok hizmet ve/veya koruma yönü ağır basan, su kalitesini iyileştirme, karbon tutma, toprak koruma, yaban hayatını ve biyolojik çeşitliliği koruma, rekreasyon firsatları sağlama, estetik gibi işlevlerinin artan önemi "çok yönlü faydalanma" ilkesini ormancilığa kazandırmıştır (Kaya, 2002). Bu durum orman kaynaklarından beklentilerin bugün için karşılanması yanında gelecek nesiller için de korunması ve aktarılması, yani sürdürülebilir yönetimini günümüzde yükselen bir değer haline getirmiştir. Bu nedenle orman kaynakları yönetimi, zamanla 
değişen politikalara ve taleplere göre yönlendirilebilen esnek bir yapıya sahip olmalıdır. Bu da ancak etkin bir şekilde hazırlanan ve mevcut durumdaki değişmelere göre revize edilebilen işlevsel planlarla mümkün olabilmektedir (Güngör, 2010). Bu planlardaki temel amaç sahip olunan doğal kaynakların sürdürülebilir ve etkin bir şekilde değerlendirilmesidir. Türkiye'de ormanlar, Orman ve Su İşleri Bakanlığı'na bağlı Orman Genel Müdürlüğü (OGM) bünyesinde faaliyet gösteren Devlet Orman İşletmeleri (DOİ) ve bunlara bağlı Orman İșletme Șeflikleri tarafindan idare edilmektedir. Ormancılık faaliyetlerinin bir bütün olarak planlanıp yürütülmesindeki en temel birimler olarak DOI'ler kabul edilmektedir. Çeşitli dönemlerde örgüt yapısında bir takım değişiklikler olsa da ekonomik bir birim olarak kabul edilen DOI'lerin asıl görevi, toplumun orman kaynaklarından beklediği mal ve hizmetleri sürdürülebilir orman yönetimi çerçevesinde sağlamaktır (Bayramoğlu, 2013). Bu amaç doğrultusunda yatırım, yönetim ve üretim gibi faaliyetlerin yoğun olarak gerçekleştirildiği birim olan DOI'lerin bu faaliyetleri etkin bir șekilde yürütmesi de son derece önemlidir (Ardıç ve ark., 2009). DOİ'lerin sahip oldukları kaynakları etkin bir şekilde kullanımı, DOI'lerde etkinlik ve etkinlik ölçümü konularını gündeme getirmektedir. Mevcut girdileri kullanarak en fazla çıktıyı üretmek veya belirli bir çıktıyı üretmek için en az girdiyi kullanmak olarak tanımlanabilen etkinlik, mevcut kaynakların kullanımıyla ilgili bir kavramdır (Baş ve Artar, 1991). Etkinlik; hedeflere ulaşma derecesini ve istenilen etki ile gerçekleșen etki arasındaki ilișkiyi ifade etmektedir (Gülcü ve ark., 2004). Günümüzde yaşanan yoğun rekabet, işletmeleri kaynaklarını etkin ve verimli şekilde kullanmaya, rekabet ettikleri sektör içindeki performanslarını göreli olarak değerlendirmeye ve etkinlik sınırında yer almak için referans almaları gereken işletmeleri belirlemeye zorlamaktadır (Ertuğrul ve Tuş Işık, 2008). Çalışmada bu amaçla Doğu Karadeniz Bölgesinde (DKB) faaliyet gösteren 21 DOİ'nin etkinlik düzeylerinin belirlenmesinde göz önünde bulundurulması gereken değişkenler ortaya konulmuştur. Belirlenen bu değişkenler yardımıyla DOI'lerin etkinlik düzeyleri belirlenmiştir. DOİ'nin etkinlik düzeylerine göre birbirleriyle karşılaştırılmaları yapılarak referans DOİ'lere göre sahip oldukları kaynakları daha etkin kullanmaları yönünde çözüm önerileri geliştirilmiştir.

\section{Materyal}

Araştırma Doğu Karadeniz Bölgesinde faaliyet gösteren 3 adet OBM'de gerçekleştirilmiştir. Trabzon OBM'de, Bayburt, Gümüşhane, Rize ve Trabzon, Artvin OBM'de, Artvin, Giresun OBM'de, Giresun ve Ordu illeri yer almaktadır. Bu bölgenin toplam alanı 3.515.772 ha olup ülke alanın \%4.47'sini oluşturmaktadır ve bu alanın \%39.78'si ormanlarla kaplıdır. Türkiye'nin \%27.6'sının ormanlarla kaplı olduğu göz önüne alındığında araştırma bölgesi orman varlığının Türkiye ortalamasından daha yüksek olduğu ifade edilebilir. Araștırma alanında faaliyet gösteren OBM'lerin sahip olduğu ormanlık alan toplamı 1.398.588 ha ve Türkiye ormanlarının \%6.45'ine karşıllk gelmektedir (OGM, 2012). Çalışma alanındaki nüfus 2012 yılı sayım sonuçlarına göre 2.621.071 kişi olup bu oran ülke nüfusunun yaklaşık \%3.46's1 kadardır. Bölgede 2010 yılı sonu ile 1.647 orman köyü ve 436.240 orman köylüsü yaşamaktadır (OGM, 2010a). Çalışmanın gerçekleştirildiği 2005-2010 yıllıları arasında bölgede 21 DOİ faaliyet gösterirken, Orman Genel Müdürlüğü bünyesinde gerçekleştirilen yeni yapılanmadan dolayı günümüzde Trabzon OBM bünyesinde 8 adet, Giresun OBM'de 10 ve Artvin OBM'de de 6 olmak üzere toplam 24 DOİ faaliyet göstermektedir. Çalışma kapsamında 21 DOİ değerlendirilmiştir.

Çalışmanın gerçekleştirildiği OBM'ler ve bunlara bağlı DOI'ler Şekil 1'de verilmiştir. 


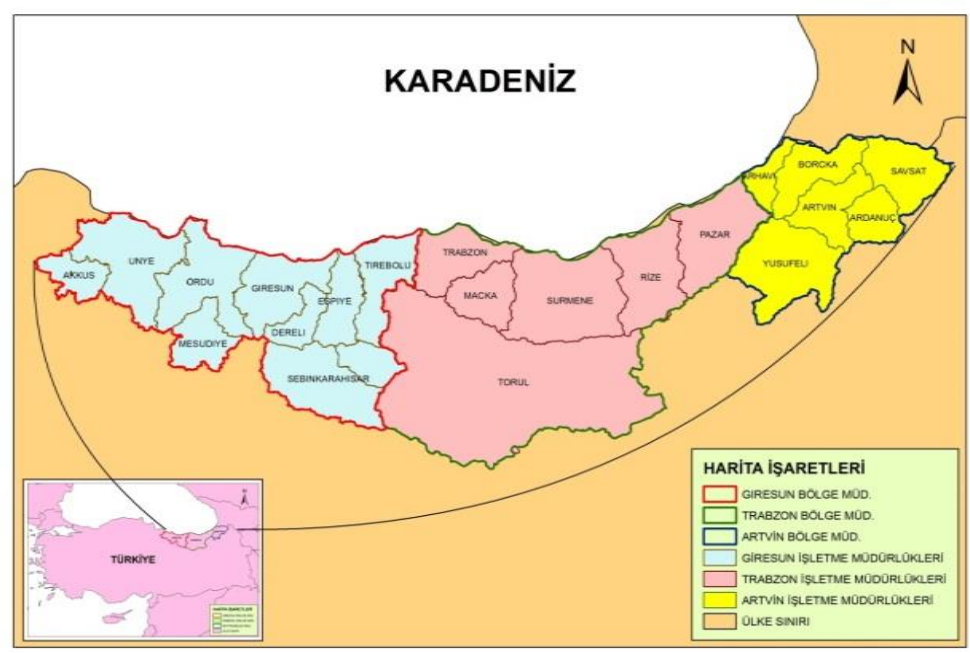

Şekil 1. Çalışma alanında faaliyet gösteren bölge müdürlükleri ve devlet orman işletmeleri

Çalışmanın gerçekleştirildiği dönemde Giresun OBM'de 44, Trabzon OBM'de 36 ve Artvin OBM'de 34 olmak üzere toplam 114 adet orman işletme şefliği bulunmaktadır. Çalışma alanındaki DOI'lerin genel özelliklerine ilişkin bilgiler Tablo 1'de verilmiştir.

Tablo 1. Çalışma bölgesinde DOİ'ye ait özellikler

\begin{tabular}{|c|r|r|r|r|}
\hline Doİ & \multicolumn{1}{|c|}{$\begin{array}{c}\text { Alan } \\
\text { (ha) }\end{array}$} & \multicolumn{1}{c|}{$\begin{array}{c}\text { Servet } \\
\left(\mathbf{m}^{\mathbf{3}}\right)\end{array}$} & $\begin{array}{c}\text { Personel } \\
\text { (kişi) }\end{array}$ & \multicolumn{1}{c|}{$\begin{array}{c}\text { Nüfus } \\
\text { (kişi) }\end{array}$} \\
\hline Trabzon & 133694.5 & 5296009.3 & 165.5 & 484005 \\
\hline Sürmene & 294996.9 & 8521355.1 & 72.7 & 192075 \\
\hline Maçka & 98337.9 & 8813147.4 & 76.7 & 20638 \\
\hline Rize & 186350.4 & 5107031 & 54.7 & 137158 \\
\hline Pazar & 181627.6 & 7521779.5 & 55.2 & 90037 \\
\hline Torul & 951563.8 & 11758360.4 & 113.3 & 25427 \\
\hline Giresun & 157725.9 & 7627920.7 & 227.7 & 208253 \\
\hline Dereli & 61300 & 3862172.6 & 47.8 & 16447 \\
\hline Espiye & 95075.3 & 6502520.5 & 83 & 56493 \\
\hline Ş.Karahisar & 268277 & 5109423.8 & 39.7 & 25383 \\
\hline Tirebolu & 137649.2 & 4308669 & 95.3 & 77508 \\
\hline Akkuş & 69742.4 & 4866827.8 & 33 & 25609 \\
\hline Mesudiye & 95691.1 & 4534051.1 & 41 & 15882 \\
\hline Ordu & 200387 & 6015978.4 & 132.8 & 255791 \\
\hline Ünye & 223879.6 & 3902027 & 84.2 & 337793 \\
\hline Artvin & 108989.4 & 12917897.7 & 396 & 33333 \\
\hline Ardanuç & 75015.6 & 5469697.5 & 113.2 & 11540 \\
\hline Arhavi & 48978.5 & 10139834.3 & 66.2 & 42237 \\
\hline Borçka & 118785 & 15420296 & 144 & 24071 \\
\hline Şavşat & 134189.4 & 6803834.2 & 121.2 & 17932 \\
\hline Yusufeli & 224673.2 & 5377438.5 & 63.5 & 21725 \\
\hline & & & &
\end{tabular}




\section{Yöntem}

Çalışmada kamu kuruluşlarının, yani kar amacı gütmeyen işletmelerin etkinliklerini ölçebilmek için geliştirilmiş olan doğrusal programlama tabanlı ve parametrik olmayan bir yöntem olan ve kendi içinde farklı modellerle tanımlanabilen Veri Zarflama Analizi (VZA) kullanılmıştır. VZA, birbirinden farklı ölçülerle ölçülmüş ya da farklı ölçü birimlerine sahip girdi ve çıktı değerlerinin karşılaştırılmasının güç olduğu durumlarda karar verme birimlerinin (KVB) göreli performanslarını olușturarak en uygun kararın alınmasına yardımcı olan bir analizdir (Charnes ve ark., 1989). Araştırmada DOİ'lerin sahip oldukları kaynaklardan minimum girdiyle maksimum çıktıyı almayı amaçlayan Girdiye Yönelik CCR yöntemi kullanılmıştır. Ölçeğe göre sabit getiri varsayımını temel alan bu yöntem, çıktı seviyesini değiştirmeden, en etkin şekilde bu çıktı düzeyini elde etmek için girdi bileşiminin ne kadar azaltılması gerektiğini araştıran model olarak tanımlamaktadır.

Girdiye yönelik model aşağıdaki şekilde kurulmaktadir.

İncelenen sistemde, $s$ tane çıktı faktörü, $m$ tane girdi faktörü kullanılarak üretilmektedir. Her biri bir gözlem olan $\mathrm{N}$ tane karar birimi içinden karar birimi $k^{\prime}$ nın, $k=1, \ldots \ldots, \mathrm{N}$, kullandığı girdi $i, i=1, \ldots \ldots \ldots . m$, miktarı $X_{i k}$ ve ürettiği çıktı miktarı $r, r=1, \ldots \ldots \ldots \ldots . . s$, miktarı $Y_{r k}, x_{i j}: j$. karar biriminin kullandığ $i$. girdi miktarı, $y_{r j}: j$. karar biriminin kullandığ $r$. çıktı miktarı, olarak tanımlanmıştır.

\section{Model}

Max

$$
\begin{aligned}
& \theta_{k}=\sum_{r=1}^{s} u_{r k} y_{r k} \\
& \text { st. } \\
& \sum_{i=1}^{m} v_{i k} x_{i k}=1 \\
& \sum_{r=1}^{s} u_{r k} y_{r j}-\sum_{i=1}^{m} v_{i k} x_{i j} \leq 0 \quad j=1, \ldots \ldots . . N \\
& u_{r k} \geq 0, v_{i k} \geq 0 \quad r=1, \ldots \ldots . s, i=1, \ldots \ldots . m
\end{aligned}
$$

Etkinliği ölçülen $k$ karar birimi için $\theta^{*}=1, v_{i k}{ }^{*}>$ 0 ve $u_{r k}{ }^{*}>0$ olmak üzere en az bir $v^{*}, u^{*}$ optimal çözümü varsa KVB etkindir.

Yönteme ilişkin matematiksel formüller ve literatürde bu yöntemin kullanıldığ ormancılık çalışmaları özetlenerek kullanılan girdi ve çıktı değişkenleri belirlenmiş ve bu yollar model değerlendirilmiştir. $\mathrm{Bu}$ değerlendirme sonucunda çalışmada kullanılacak 5 girdi ve 3 çıktı değişkenleri belirlenmiştir. Bunlar;

Girdi Değișkenleri

- DOİ Genel Alanı $\left(X_{l}\right)$

- DOİ Serveti $\left(X_{2}\right)$

- DOİ Genel Alanı İçindeki $\operatorname{Nüfus}\left(X_{3}\right)$

- DOİ Personel Sayısı $\left(X_{4}\right)$

- DOİ Toplam Giderleri $\left(X_{5}\right)$

Çıktı Değişkenleri

- DOİ Üretim Miktarı $\left(Y_{l}\right)$

- DOİ Satış Miktarı $\left(Y_{2}\right)$

- DOİ Toplam Gelir $\left(Y_{3}\right)$ dir.

Araştırmada DOİ'lerin etkinlik düzeyleri 4 farklı durum altında değerlendirilmiştir. Her bir durumda VZA'da kullanılan girdiçıktılarda değişiklikler yapılmıştır.

$\mathrm{Bu}$ kapsamda oluşturulan amaç fonksiyonu aşağıda verilmiştir.

$$
\begin{aligned}
& \max \left(u_{1} Y_{1}+u_{2} Y_{2}+u_{3} Y_{3}\right) \\
& \left(v_{1} X_{1}+v_{2} X_{2}+v_{3} X_{3}+v_{4} X_{4}+v_{5} X_{5}\right)=1 \\
& \left(u_{1} Y_{1}+u_{2} Y_{2}+u_{3} Y_{3}\right)-\left(v_{1} X_{1}+v_{2} X_{2}+\right. \\
& \left.v_{3} X_{3}+v_{4} X_{4}+v_{5} X_{5}\right) \leq 0 \\
& u_{1}, u_{2}, u_{3} \geq 0 \\
& v_{1}, v_{2}, v_{3}, v_{4}, v_{5} \geq 0
\end{aligned}
$$

max ile belirtilen birinci satır amaç fonksiyonunu, diğer satırlar ise kısıtları göstermektedir. Fonksiyondaki $(X)$ girdi değişkenleri, $(Y)$ çıktı değişkenleri, $(v)$ girdilerin ağırlıklarını ve $(u)$ çıktıların ağırlıklarını göstermektedir.

Çalışmada DOI'nin etkinlik düzeylerini belirlemede 4 farklı durum için VZA analizi uygulanmıştır. Bunlar;

I. Durum; Araştırma bölgesindeki DOI'lerin mevcut durumları ortaya konulmasına yönelik VZA analizi uygulanmıştır.

II. Durum; Araştırma bölgesindeki DOİ'lerin alanları içinde kalan "Arazi Tahsis Bedelleri" ve işletmelerin sosyal fonksiyonlar kapsamında "Kanuni Haklar" başlığı altında gerçekleştirdikleri indirimli satışlar değerlendirilerek DOI'lerin çıtı değişkenlerinden gelirler bölümüne eklenmiştir. 
III. Durum; Araştırma bölgesindeki DOİ'ler bağımsız birer işletme olarak değerlendirilmiştir. II. Duruma ek olarak DOI'lerin tüm giderleri hesaplanarak VZA'da toplam giderlere eklenmiştir.

IV. Durum; Araştırma bölgesindeki DOI'lerin ekolojik fonksiyonlarının ekonomik değerleri hesaplanmıştır. $\mathrm{Bu}$ kapsamda DOİ'lerin amenajman planlarında yer alan "ekoturizm ve rekreasyon, erozyon önleme ve hidrolojik" amaçlı ayrılan alanlar belirlenmiştir. DOI'lerin yıllık artım değerlerinden de "karbon tutma" miktarları hesaplanmıştır. Son aşamada ise fonksiyonların ekonomik değerleri hesap edilerek toplamları VZA'da çıktı değişkenlerinden toplam gelirlere eklenmiştir. $\mathrm{Bu}$ fonksiyonların ekonomik değerleri Asan ve ark. (2002) de ki katsayılardan ve fayda transferi yönteminden yararlanılmıştır.

Tablo 2. I. durum VZA'da kullanılan değişkenler

\begin{tabular}{|c|c|c|c|c|c|c|c|c|}
\hline $\begin{array}{c}\text { Devlet } \\
\text { Orman } \\
\text { İşletmesi }\end{array}$ & $\begin{array}{c}\text { Alan } \\
\text { (ha) }\end{array}$ & $\begin{array}{c}\text { Servet } \\
\left(\mathbf{m}^{3}\right)\end{array}$ & $\begin{array}{c}\text { Personel } \\
\text { (kişi) }\end{array}$ & $\begin{array}{c}\text { Nüfus } \\
\text { (kişi) }\end{array}$ & $\begin{array}{c}\text { Giderler } \\
\text { Toplamı } \\
\text { (TL) }\end{array}$ & $\begin{array}{c}\text { Üretim } \\
\text { Miktarı } \\
\left(\mathbf{m}^{3}\right)\end{array}$ & $\begin{array}{c}\text { Satış } \\
\text { Miktarı } \\
\left(\mathbf{m}^{3}\right) \\
\end{array}$ & $\begin{array}{c}\text { Gelirler } \\
\text { Toplamı } \\
\text { (TL) }\end{array}$ \\
\hline Trabzon & 133694.5 & 5296009.3 & 165.5 & 484005 & 4904448 & 37953.3 & 21257.5 & 1321568.3 \\
\hline Sürmene & 294996.9 & 8521355.1 & 72.7 & 192075 & 1045632.5 & 17476.2 & 9454.5 & 692923 \\
\hline Maçka & 98337.9 & 8813147.4 & 76.7 & 20638 & 2489278.7 & 57606.2 & 28415.5 & 2777833.2 \\
\hline Rize & 186350.4 & 5107031 & 54.7 & 137158 & 1004261.8 & 18527.7 & 10060.8 & 600533.2 \\
\hline Pazar & 181627.6 & 7521779.5 & 55.2 & 90037 & 1557248.8 & 10056.7 & 4330.2 & 348706.7 \\
\hline Torul & 951563.8 & 11758360.4 & 113.3 & 25427 & 5825319.3 & 107761.2 & 46642.9 & 4806322.7 \\
\hline Giresun & 157725.9 & 7627920.7 & 227.7 & 208253 & 8792975.7 & 83932 & 46234.1 & 3774999.7 \\
\hline Dereli & 61300 & 3862172.6 & 47.8 & 16447 & 2864493.4 & 55345.6 & 30341.3 & 2847523.5 \\
\hline Espiye & 95075.3 & 6502520.5 & 83 & 56493 & 3899756.7 & 71666.6 & 34792.8 & 3020759 \\
\hline Ş.Karahisar & 268277 & 5109423.8 & 39.7 & 25383 & 1459818.7 & 25223.3 & 14972.0 & 1067964.7 \\
\hline Tirebolu & 137649.2 & 4308669 & 95.3 & 77508 & 3635075.6 & 55196.5 & 25925.6 & 3036660.4 \\
\hline Akkuş & 69742.4 & 4866827.8 & 33 & 25609 & 3380795.1 & 102271.6 & 53781.5 & 3869113.3 \\
\hline Mesudiye & 95691.1 & 4534051.1 & 41 & 15882 & 3114683.9 & 116372.6 & 58120.9 & 4271895.8 \\
\hline Ordu & 00387 & 6015978.4 & 132.8 & 255791 & 3705835.6 & 63897.7 & 29580.1 & 2798270.2 \\
\hline Ünye & 223879.6 & 3902027 & 84.2 & 337793 & 2319217.2 & 50266.9 & 25311.1 & 1872744.7 \\
\hline Artvin & 108989.4 & 12917897.7 & 396 & 33333 & 15513592.7 & 137062.1 & 69860.1 & 7950176.8 \\
\hline Ardanuç & 75015.6 & 5469697.5 & 113.2 & 11540 & 3606972 & 69584.1 & 39212.9 & 3128529.2 \\
\hline Arhavi & 48978.5 & 10139834.3 & 66.2 & 42237 & 1795108.8 & 19801.8 & 10568.4 & 837096.2 \\
\hline Borçka & 118785 & 15420296 & 144 & 24071 & 4766153.2 & 56681.1 & 31208.9 & 2383663.2 \\
\hline Şavşat & 134189.4 & 6803834.2 & 121.2 & 17932 & 4040247.2 & 54702.8 & 31237.6 & 2582936.8 \\
\hline Iusufeli & 224673.2 & 5377438.5 & 63.5 & 21725 & 1660364.3 & 23462.9 & 14949.4 & 528190.8 \\
\hline
\end{tabular}

DOI'lerin bağlı bulundukları OGM, 2005 yılında Katma Bütçe, 2006 yılında Genel Bütçe ve 2007 yılından itibaren Özel Bütçeli kurum statüsündedir. DOI'lerin üretim ve pazarlama harcamaları dışında toplumun tümü için faydalar oluşturan bir çok faaliyeti 
de döner sermaye bütçesinden ödenmektedir. $\mathrm{Bu}$ amaç doğrultusunda "Katma-Genel ve Özel Bütçe Giderleri" Artvin, Giresun ve Trabzon Defterdarlıkları ve OBM'nin özel bütçe kalemlerinden temin edilmiştir. $\mathrm{Bu}$ bütçe harcamaları hesaplanarak VZA'da toplam gider değişkenine eklenmiştir.

\section{Bulgular}

I. durumda, bölgede faaliyet gösteren DOI'lerin mevcut durumları ortaya konulmaya çalışılmıştır. $\mathrm{Bu}$ kapsamda VZA'da kullanılan 8 değişkenin (2005-2010 yılları aritmetik ortalama değerleri) değerleri Tablo 3'de verilmiştir.

Tablo 3. I. durum VZA değerleri (2005-2010 yıl1)

\begin{tabular}{|c|c|c|c|c|c|}
\hline İşletme Adı & $\begin{array}{c}\text { Etkinlik } \\
\text { Değeri }\end{array}$ & İşletme Adı & $\begin{array}{c}\text { Etkinlik } \\
\text { Değeri }\end{array}$ & İşletme Adı & $\begin{array}{c}\text { Etkinlik } \\
\text { Değeri }\end{array}$ \\
\hline Akkuş & 1 & Giresun & 0.530492 & Şavşat & 0.534453 \\
\hline Ardanuç & 1 & Maçka & 0.813628 & Ş.Karahisar & 0.549620 \\
\hline Arhavi & 0.360321 & Mesudiye & 1 & Tirebolu & 0.748030 \\
\hline Artvin & 1 & Ordu & 0.550550 & Torul & 0.701315 \\
\hline Borçka & 0.421575 & Pazar & 0.172847 & Trabzon & 0.313125 \\
\hline Dereli & 0.903180 & Rize & 0.536868 & Ünye & 0.588749 \\
\hline Espiye & 0.630358 & Sürmene & 0.484553 & Yusufeli & 0.482505 \\
\hline
\end{tabular}

Tablo 3 incelendiğinde I. durum için yapılan VZA sonuçlarına göre 21 DOİ'den sadece 4 DOİ, Akkuş, Ardanuç, Artvin ve Mesudiye
DOİ'leri etkin çıkmışlardır. Etkin olmayan 17 DOİ'nin referans alması gereken DOİ'ler ve referans düzeyleri Tablo 4'de verilmiştir.

Tablo 4. I. durum VZA referans düzeyleri

\begin{tabular}{|c|c|l|c|c|}
\hline İşletme Adı & Etkinlik Değeri & \multicolumn{3}{|c|}{ Referans Devlet Orman İşletmesi } \\
\hline Arhavi & 0.360321 & Akkuş $(0.651691)$ & Mesudiye $(0.1369297)$ & \\
\hline Borçka & 0.421575 & Akkuş $(0.1072354)$ & Artvin $(0.2174600)$ & $\begin{array}{c}\text { Mesudiye } \\
(0.4203923)\end{array}$ \\
\hline Dereli & 0.90318 & Akkuş $(0.3697265)$ & Artvin(0.3128810) & $\begin{array}{c}\text { Mesudiye } \\
(0.2734765)\end{array}$ \\
\hline Espiye & 0.630358 & Akkuş $(0.4569195)$ & Mesudiye $(0.2932856)$ & - \\
\hline Giresun & 0.530492 & Akkuş $(0.5247148)$ & Mesudiye $(0.8361584)$ & - \\
\hline Maçka & 0.813628 & Mesudiye $(0.6502577)$ & - & - \\
\hline Ordu & 0.55055 & Mesudiye $(0.6550418)$ & - & - \\
\hline Pazar & 0.172847 & Mesudiye $(0.8641811)$ & - & - \\
\hline Rize & 0.536868 & Mesudiye $(0.1731012)$ & - & - \\
\hline Sürmene & 0.484553 & Mesudiye $(0.1626695)$ & - & - \\
\hline Şavşat & 0.534453 & Ardanuç $(0.2082147)$ & Mesudiye $(0.4521485)$ & - \\
\hline Ş.Karahisar & 0.54962 & Mesudiye $(0.2576010)$ & - & - \\
\hline Tirebolu & 0.74803 & Mesudiye $(0.7108461)$ & - & - \\
\hline Torul & 0.701315 & Ardanuç $(0.4007254)$ & Mesudiye $(0.8316311)$ & - \\
\hline Trabzon & 0.313125 & Mesudiye $(0.3657462)$ & - & - \\
\hline Ünye & 0.588749 & Mesudiye $(0.4383873)$ & - & - \\
\hline Yusufeli & 0.482505 & Mesudiye $(0.2572121)$ & - & - \\
\hline
\end{tabular}


I. duruma göre Mesudiye DOİ, etkin olmayan 17 DOI'nin tümü tarafindan da referans alınmıştır. Analiz sonucunda etkin olmayan DOI'lerin etkin duruma gelebilmeleri için girdi ve çıktı değişkenlerine ait hedef değerleri ve oranları da hesaplanmaktadır. $\mathrm{Bu}$ çalışma kapsamında hedef değerler ve değişim oranları örnek olması amacıyla Giresun DOİ için hesaplanmıştır. Tablo 4'e göre 0.530492 etkinlik düzeyine sahip olan Giresun DOİ etkin olan Akkuş ve Mesudiye DOI'lerini sirasiyla 0.5247148 ve 0.8361584 düzeyinde referans almas1 gerekmektedir.
Tablo 2'de bu DOI'lerin toplam alan $\left(X_{1}\right)$ değişken değerleri ile Tablo 4.'deki referans düzeylerinden yararlanılarak, Giresun DOİ'nin $\left(X_{1}\right)$ değişkenine ait hedef değeri;

$-X_{1}=[(0.5247148) \times(69742.4)+$ $(0.8361584) \times(95691.1)]=116607.79 \mathrm{ha}$. ve değişim oranı ise; $\frac{[(116607.79-157725.92) \times 100]}{157725.92}=-\% 26.07$ olarak hesaplanmıştır.

Giresun DOİ'nin için tüm girdi ve çıktı değişkenleri benzer biçimde hesaplanmış olup Tablo 5'de verilmiştir.

Tablo 5. Giresun DOİ hedef değerler ve değişim yüzdeleri

\begin{tabular}{|c|c|c|c|c|c|}
\hline \multirow{2}{*}{ Değişkenler } & \multicolumn{2}{|c|}{$\begin{array}{c}\text { Referans Gösterilen } \\
\text { Devlet Orman İletmeleri }\end{array}$} & \multicolumn{3}{|c|}{ Giresun Devlet Orman İşletmesi } \\
\cline { 2 - 6 } & $\begin{array}{c}\text { Akkuş } \\
(\mathbf{0 . 5 2 4 7 1 4 8})\end{array}$ & $\begin{array}{c}\text { Mesudiye } \\
\mathbf{( 0 . 8 3 6 1 5 8 4 )}\end{array}$ & $\begin{array}{c}\text { Mevcut } \\
\text { Durum }\end{array}$ & Hedef Değer & $\begin{array}{c}\text { Değişim } \\
\text { Oranı(\%) }\end{array}$ \\
\hline$X_{1}$ & 69742.35 & 95691.13 & 157725.9 & 116607.79 & -26.07 \\
\hline$X_{2}$ & 4866827.75 & 4534051.15 & 7627920.7 & 6344881.50 & -16.82 \\
\hline$X_{3}$ & 33 & 41 & 227.7 & 51.60 & -77.34 \\
\hline$X_{4}$ & 25609 & 15882 & 208253 & 26717.29 & -87.17 \\
\hline$X_{5}$ & 3380795.09 & 3114683.88 & 8792975.7 & 4378322.31 & -50.21 \\
\hline$Y_{1}$ & 102271.55 & 57606.20 & 83932 & 150969.28 & 79.87 \\
\hline$Y_{2}$ & 53781.51 & 28415.54 & 46234.1 & 76818.25 & 66.15 \\
\hline$Y_{3}$ & 3869113.30 & 2777833.20 & 3774999.7 & 5602162.57 & 48.40 \\
\hline
\end{tabular}

Tablo 5 incelendiğinde, Giresun DOİ'nin etkin duruma gelebilmesi için girdi değişkenleri olan işletme genel alanının \%26.07 azaltılarak 116607.79 ha.'ya, sahip olduğu servet miktarının \%16.82 azaltılarak $6344881.50 \mathrm{~m}^{3}$ 'e, personel sayısinın \%77.34 azaltılarak yaklaşık 52 kişiye, işletme alanı içinde yaşayan nüfusun $\% 87.17$ azaltılarak yaklaşık 26717 kişiye ve giderlerinin \%50.21 azaltılarak 4378322.31 TL'ye indirilmesi gerekmektedir. Çıktı değişkenlerinin ise; üretim miktarının \%79.87 arttırılarak $150969.28 \mathrm{~m}^{3}$ 'e, satış miktarının \%66.15 arttırilarak $76818.25 \mathrm{~m}^{3} \mathrm{e}$ ve gelirlerinin \%48.4 arttırılarak 5602162.57 TL'ye çıkarılması gerekmektedir. II. Durumda, çıktı değişkenlerinden toplam gelire DOI'lerin sağlamış olduğu "Sosyal fonksiyon" ve işletme müdürlüğü sahası içinde kalmasına rağmen işletme muhasebe kayıtlarına yansitılmayan "Arazi Tahsis Bedelleri" eklenmiştir. 2005-2010 y1lları için 21 DOI'nin sosyal fonksiyonlarının toplam ekonomik değeri 9.517.237,2 TL (\%17.4) ve arazi tahsis bedelleri toplamı 8.625.342,5 TL (\%15.8)'dir. Hesaplanan bu değerler DOİ'lerin toplam gelirleri üzerinde $18.142 .579,7$ TL (\%33.2) artış sağlamıştır. II. duruma ilişkin VZA sonuçlarına göre 21 işletmeden sadece 5 DOİ (Akkuş, Ardanuç, Artvin, Mesudiye ve Sürmene) etkin çıkmıştır. II. durum için elde edilen VZA sonuçları Tablo 6'da verilmiştir. 
Tablo 6. II. durum VZA değerleri.

\begin{tabular}{|c|c|c|c|c|c|}
\hline İșletme Adı & $\begin{array}{c}\text { Etkinlik } \\
\text { Değeri }\end{array}$ & İşletme Adı & Etkinlik Değeri & $\begin{array}{c}\text { İşletme } \\
\text { Adı }\end{array}$ & $\begin{array}{c}\text { Etkinlik } \\
\text { Değeri }\end{array}$ \\
\hline Akkuş & 1 & Giresun & 0.590697 & Şavşat & 0.586639 \\
\hline Ardanuç & 1 & Maçka & 0.789210 & Ş.Karahisar & 0.709967 \\
\hline Arhavi & 0.332190 & Mesudiye & 1 & Tirebolu & 0.799386 \\
\hline Artvin & 1 & Ordu & 0.525369 & Torul & 0.913028 \\
\hline Borçka & 0.526599 & Pazar & 0.231241 & Trabzon & 0.313125 \\
\hline Dereli & 0.874482 & Rize & 0.578329 & Ünye & 0.607812 \\
\hline Espiye & 0.590927 & Sürmene & 1 & Yusufeli & 0.622567 \\
\hline
\end{tabular}

Etkin olmayan 16 DOİ'nin referans alması gereken DOI'ler ve referans düzeyleri Tablo 7'de verilmiştir.

Tablo 7. II. durum VZA referans düzeyleri

\begin{tabular}{|c|c|c|c|c|}
\hline İşletme Adı & Etkinlik Değeri & \multicolumn{3}{|c|}{ Referans Devlet Orman İşletmesi } \\
\hline Arhavi & 0.332190 & $\begin{array}{c}\text { Akkuş } \\
(0.0600812)\end{array}$ & $\begin{array}{c}\text { Mesudiye } \\
(0.1262393)\end{array}$ & \\
\hline Borçka & 0.526599 & $\begin{array}{c}\text { Akkuş } \\
(0.1339504) \\
\end{array}$ & $\begin{array}{c}\text { Artvin } \\
(0.0271635) \\
\end{array}$ & $\begin{array}{c}\text { Mesudiye } \\
(0.5251222)\end{array}$ \\
\hline Dereli & 0.874482 & $\begin{array}{c}\text { Akkuş } \\
(0.3579786) \\
\end{array}$ & $\begin{array}{c}\text { Artvin } \\
(0.0302940) \\
\end{array}$ & $\begin{array}{c}\text { Mesudiye } \\
(0.2647869)\end{array}$ \\
\hline Espiye & 0.590927 & $\begin{array}{c}\text { AkkuŞ } \\
(0.4283381)\end{array}$ & $\begin{array}{c}\text { Mesudiye } \\
(0.2749399)\end{array}$ & 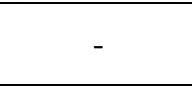 \\
\hline Giresun & 0.590697 & $\begin{array}{c}\text { Akkuş } \\
(0.0584263) \\
\end{array}$ & $\begin{array}{c}\text { Mesudiye } \\
(0.9310517)\end{array}$ & - \\
\hline Maçka & 0.789210 & $\begin{array}{c}\text { Mesudiye } \\
(0.6194705)\end{array}$ & $\begin{array}{c}\text { Sürmene } \\
(0.0335769)\end{array}$ & - \\
\hline Ordu & 0.525369 & $\begin{array}{c}\text { Mesudiye } \\
(0.6094241)\end{array}$ & $\begin{array}{c}\text { Sürmene } \\
(0.0466416)\end{array}$ & - \\
\hline Pazar & 0.231241 & $\begin{array}{c}\text { Mesudiye } \\
(0.0814858)\end{array}$ & $\begin{array}{c}\text { Sürmene } \\
(0.1016589)\end{array}$ & \\
\hline Rize & 0.578329 & $\begin{array}{c}\text { Mesudiye } \\
(0.1605340)\end{array}$ & $\begin{array}{c}\text { Sürmene } \\
(0.0772560)\end{array}$ & \\
\hline Şavşat & 0.586639 & $\begin{array}{c}\text { Ardanuç } \\
(0.2285452)\end{array}$ & $\begin{array}{c}\text { Mesudiye } \\
(0.4962972)\end{array}$ & \\
\hline Ş.Karahisar & 0.709967 & $\begin{array}{c}\text { Mesudiye } \\
(0.3098578) \\
\end{array}$ & $\begin{array}{c}\text { Sürmene } \\
(0.0682022)\end{array}$ & \\
\hline Tirebolu & 0.799386 & $\begin{array}{c}\text { Mesudiye } \\
(0.7596495)\end{array}$ & & \\
\hline Torul & 0.913028 & $\begin{array}{c}\text { Ardanuç } \\
(0.5216964)\end{array}$ & $\begin{array}{c}\text { Mesudiye } \\
(1.082684)\end{array}$ & \\
\hline Trabzon & 0.313125 & $\begin{array}{c}\text { Mesudiye } \\
(0.3657462)\end{array}$ & 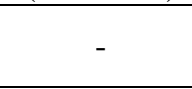 & \\
\hline Ünye & 0.607812 & $\begin{array}{c}\text { Mesudiye } \\
(0.4372492)\end{array}$ & $\begin{array}{c}\text { Sürmene } \\
(0.0456724)\end{array}$ & \\
\hline Yusufeli & 0.622567 & Mesudiye & Sürmene & \\
\hline
\end{tabular}




\section{\begin{tabular}{|l|l|l|l} 
& & $(0.3170368)$ & $(0.04420199)$ \\
\hline
\end{tabular}}

III. durumda araştırma alanındaki 21 DOİ birer bağımsız işletme şeklinde kabul edilmiştir. Bu kapsamda II. Duruma ek olarak toplam giderler değişkenine "Katma- Genel ve Özel Bütçe Giderleri" de eklenmiştir. Bütçe giderleri toplam giderler üzerinde
25.369.586,8 TL'lik (\%31.17) bir artış sağlamıştır. III. durumda yapılan VZA sonuçlarına göre 21 işletmeden sadece 4 DOİ (Ardanuç, Akkuş, Artvin ve Mesudiye)etkin çıkmışıtır. III. durum için elde edilen VZA sonuçları Tablo 8'de verilmiştir.

Tablo 8. III. durum VZA değerleri

\begin{tabular}{|c|c|c|c|c|c|}
\hline $\begin{array}{c}\text { İşletme } \\
\text { Adı }\end{array}$ & $\begin{array}{c}\text { Etkinlik } \\
\text { Değeri }\end{array}$ & İşletme Adı & $\begin{array}{c}\text { Etkinlik } \\
\text { Değeri }\end{array}$ & İşletme Adı & $\begin{array}{c}\text { Etkinlik } \\
\text { Değeri }\end{array}$ \\
\hline Akkuş & 1 & Giresun & 0.590697 & Şavşat & 0.583984 \\
\hline Ardanuç & 1 & Maçka & 0.651265 & Ş.Karahisar & 0.633941 \\
\hline Arhavi & 0.313844 & Mesudiye & 1 & Tirebolu & 0.799386 \\
\hline Artvin & 1 & Ordu & 0.472083 & Torul & 0.916205 \\
\hline Borçka & 0.467310 & Pazar & 0.199087 & Trabzon & 0.313125 \\
\hline Dereli & 0.874960 & Rize & 0.351725 & Ünye & 0.527366 \\
\hline Espiye & 0.549312 & Sürmene & 0.591943 & Yusufeli & 0.541886 \\
\hline
\end{tabular}

Etkin olmayan 17 DOİ'nin referans alması gereken DOİ'ler ve referans düzeyleri Tablo 9'da verilmişstir.

Tablo 9. III. durum VZA referans düzeyleri

\begin{tabular}{|c|c|c|c|c|}
\hline İşletme Adı & $\begin{array}{c}\text { Etkinlik } \\
\text { Değeri }\end{array}$ & \multicolumn{3}{|c|}{ Referans Devlet Orman İşletmesi } \\
\hline Arhavi & 0.313844 & Akkuş (0.1925651) & \begin{tabular}{|l|} 
Mesudiye $(0.0036469)$ \\
\end{tabular} & \\
\hline Borçka & 0.467310 & Akkuş (0.1200732) & $\operatorname{Artvin}(0.0388327)$ & $\begin{array}{c}\text { Mesudiye } \\
(0.5171395)\end{array}$ \\
\hline Dereli & 0.874960 & Akkuş (0.3591010) & $\operatorname{Artvin}(0.0294573)$ & $\begin{array}{c}\text { Mesudiye } \\
(0.2652279)\end{array}$ \\
\hline Espiye & 0.549312 & Akkuş (0.6639048) & Mesudiye $(0.0323787)$ & - \\
\hline Giresun & 0.590697 & Akkuş (0.0584263) & Mesudiye (0.9310517) & - \\
\hline Maçka & 0.651265 & Akkuş $(0.3687050)$ & Mesudiye $(0.2524723)$ & - \\
\hline Ordu & 0.472083 & Mesudiye $(0.6263810)$ & - & - \\
\hline Pazar & 0.199087 & Akkuş (0.1150291) & - & - \\
\hline Rize & 0.351725 & Akkuş $(0.1487222)$ & Mesudiye $(0.0354829)$ & - \\
\hline Sürmene & 0.591943 & Akkuş (0.3530732) & - & - \\
\hline Şavşat & 0.583984 & Ardanuç $(0.2648400)$ & Mesudiye $(0.4669283)$ & - \\
\hline Ş.Karahisar & 0.633941 & Akkuş $(0.3250030)$ & - & - \\
\hline Tirebolu & 0.799386 & Mesudiye (0.7596495) & - & - \\
\hline Torul & 0.916205 & Mesudiye (1.1325360) & Ardanuç(0.4600884) & - \\
\hline Trabzon & 0.313125 & Mesudiye $(0.3657462)$ & - & - \\
\hline Ünye & 0.527366 & Mesudiye $(0.4538539)$ & - & - \\
\hline Yusufeli & 0.541886 & Akkuş (0.3235013) & - & - \\
\hline
\end{tabular}

IV. durumda ormanların ve dolayısıyla DOİlerin sağladığı ekolojik fonksiyonların ekonomik değerleri hesaplanarak her bir DOI'nin toplam gelirine eklenmiştir. Giresun 
OBM bünyesindeki Dereli, Ş.Karahisar ve Tirebolu DOI'lerinin mevcut planlarında ekolojik fonksiyonların bulunmamasının yanında yeni amenajman planlarının da yapım aşamasında olmasından dolayı VZA dışında bırakılmıştır. Araştırma alanındaki DOİler için hesaplanan fonksiyon değerlerinin 57.453.904.92 TL ile toplam geliri \%78.68 arttırmıştır. $\mathrm{Bu}$ durumda yapılan VZA sonuçlarına göre 18 işletmeden 6 DOİ (Akkuş, Ardanuç, Artvin, Mesudiye, Sürmene ve Yusufeli) etkin çıkmıştır (Tablo 10).

Tablo 10. IV. durum VZA değerleri

\begin{tabular}{|c|c|c|c|c|c|}
\hline İşletme Adı & $\begin{array}{c}\text { Etkinlik } \\
\text { Değeri }\end{array}$ & İşletme Adı & $\begin{array}{c}\text { Etkinlik } \\
\text { Değeri }\end{array}$ & İşletme Adı & $\begin{array}{c}\text { Etkinlik } \\
\text { Değeri }\end{array}$ \\
\hline Akkuş & 1 & Giresun & 0.672899 & Şaş̧at & 0.497993 \\
\hline Ardanuç & 1 & Maçka & 0.691869 & Sürmene & 1 \\
\hline Arhavi & 0.281326 & Mesudiye & 1 & Torul & 0.869612 \\
\hline Artvin & 1 & Ordu & 0.464699 & Trabzon & 0.568757 \\
\hline Borçka & 0.668006 & Pazar & 0.642145 & Ünye & 0.599822 \\
\hline Espiye & 0.574232 & Rize & 0.878618 & Yusufeli & 1 \\
\hline
\end{tabular}

Etkin olmayan 12 DOI'nin referans alması gereken DOI'ler ve referans düzeyleri Tablo 11'de verilmiştir.

Tablo 11. IV. durum VZA referans düzeyleri

\begin{tabular}{|c|c|c|c|c|}
\hline İşletme Adı & $\begin{array}{c}\text { Etkinlik } \\
\text { Değeri }\end{array}$ & \multicolumn{3}{|c|}{ Referans Devlet Orman İşletmesi } \\
\hline Arhavi & 0.281326 & Akkuş $(0.1925651)$ & Mesudiye(0.0036469) & \\
\hline Borçka & 0.668006 & Akkuş(0.2286204) & Ardanuç(0.3278778) & $\begin{array}{c}\text { Mesudiye } \\
(0.4055617)\end{array}$ \\
\hline Espiye & 0.574232 & Akkuş(0.7179614) & Sürmene(0.0153322) & - \\
\hline Giresun & 0.672899 & Akkuş(0.0665571) & Mesudiye(1.060620) & - \\
\hline Maçka & 0.691869 & Akkuş(0.0169313) & Mesudiye(0.63944499) & $\begin{array}{c}\text { Sürmene } \\
(0.0192083)\end{array}$ \\
\hline Ordu & 0.464699 & Mesudiye(0.6165831) & - & - \\
\hline Pazar & 0.642145 & Mesudiye(0.1566063) & Sürmene(0.2782080) & $\begin{array}{c}\text { Yusufeli } \\
(0.0871265)\end{array}$ \\
\hline Rize & 0.878618 & Mesudiye(0.2182678) & Sürmene(0.4104385) & - \\
\hline Şavşat & 0.497993 & Ardanuç(0.2258422) & Mesudiye(0.3981730) & - \\
\hline Torul & 0.869612 & Ardanuç(0.4366909) & Mesudiye(1.0749410) & - \\
\hline Trabzon & 0.568757 & Mesudiye(0.6643374) & - & - \\
\hline Ünye & 0.599822 & Mesudiye $(0.5162096)$ & - & - \\
\hline
\end{tabular}

\section{Tartışma ve Sonuç}

VZA sonuçlarından önce dikkat çekilmesi gereken konu bölgede faaliyet gösteren DOİ sayısının 5-10 yıllık dönemlerde değişiklik göstermesidir. Araştırma alanında 1980'lerde 25 DOİ faaliyet gösterirken 1990'ların ortalarında 2 DOİ kapatılıp yerine farklı 2 DOİ açılmıştır. 2000'li yılların başında bölgede 24 DOİ faaliyet gösterirken, araştırma kapsamında ele alınan çalışma y1lları kapsamında 21 DOİ ve günümüzde ise
23 DOİ faaliyetine devam etmektedir. Yazıcı (1989) çalışmasında, bu sorunu incelemiş ve birer ekonomik birim olan DOI'lerin açıllp kapanmasında ekonomik verilere dayanılarak karar verilmesi gerektiğini ve süreklilik açısından da konunun önemli olduğunu ifade etmiştir.

Çalışmada 4 farklı durum için VZA uygulanmıştır. I. durumda mevcut değerler üzerinden hareket edilmiştir. Bu durumda kar eden sadece Akkuş, Maçka ve Mesudiye 
DOİ'leridir. Çalışma alanındaki 21 DOİ'nin toplam gelirlerinin toplam giderlerini karşılama oranı \%67'dir. I. durum için gerçekleştirilen analiz sonucunda ikisi Artvin OBM (Artvin, Ardanuç), ikisi de Giresun OBM (Akkuş, Mesudiye) olmak üzere sadece dört DOİ etkin çıkmıştır. Arhavi, Dereli ve Pazar DOI'nin özellikle çıktı miktarlarındaki hedef değerleri ve değişim oranları oldukça yüksektir. $\mathrm{Bu}$ değişkenler göz önüne alındığında 3 DOİ'nin de faaliyetlerine işletme müdürlügü seviyesinde devam etmemesi gerektiği açıkça görülmektedir.

II. durumda, DOİ'lerin sahaları içindeki alanlardan genel müdürlük tarafindan alınan arazi tahsis bedelleri ve kanuni haklar kapsamında DOI'ler tarafindan verilen indirimli satışların piyasa değerleri ile satılmas1 durumunda elde edecekleri gelirler hesap edilerek analizde çıktı değişkeni olarak kullanılan toplam gelir değişkenine eklenmiştir. Arazi tahsis bedelleri toplam gelirler üzerinde $\% 15.8$, indirimli satışlar ise \%17.4'lük artışa neden olmuştur Arazi tahsis bedelleri sırasıyla en yüksek Torul, Sürmene ve Borçka DOI'lerinde, en düşük ise Arhavi, Ardanuç ve Dereli DOI'lerinde hesaplanmıştır. İndirimli satış bedelleri en yüksek sırasıyla Akkuş, Giresun ve Artvin DOİ'lerinde, en düşük ise Sürmene, Rize ve Arhavi DOI'lerinde hesaplanmıştır. II. durumda toplam gelirlerin toplam giderleri karşılama oranı \%89.2'dir. Analiz sonucunda I. durumda etkin çıkan dört DOİ'nin yanına Sürmene DOI'de eklenmiştir. Sürmene DOİ'nin etkin çıkmasının nedeni olarak bölgede çalışma yılları içinde madencilikenerji faaliyetlerinin yoğun bir şekilde sürdürülmesi ve dolayısıyla arazi tahsis bedellerinin yüksek olması gösterilebilir. OGM, 2006 yllından itibaren özel bütçe kapsamında çalışmaya başlamıştır. 20062010 verilerine göre arazi tahsis bedellerinden elde edilen kira bedelleri özel bütçenin yaklaşık \%32.5'ni oluşturmaktadır (OGM, 2007, 2008, 2009, 2010b, 2011). Çalışma bölgesinde hesaplanan arazi tahsis bedellerinin bu değerin ancak yarınsa karşıllık geldiği tespit edilmiştir. VZA sonuçlarına incelendiğinde 12 DOI'nin etkin olabilmesi için toplam gelirlerinin yeterli olduğu görülmektedir. $\mathrm{Bu}$ nedenle arazi tahsis bedelleri Türkiye genelinin altında olmasına rağmen bölgedeki DOİler için oldukça önemlidir.

III. durumda DOİ'lerin ekonomik anlamda bağımsız birer işletme olarak düşünülmüş ve giderlerine katma- genel - özel bütçe giderleri de eklenmiştir. Bütçe giderleri toplam giderler üzerinde \%31.2'lik bir artış yaratmıştır. En yüksek bütçe giderine Giresun, Ordu ve Artvin DOİ'leri, en düşük ise Dereli, Ş.Karahisar ve Akkuş DOİ'leri sahiptir. III. durumda toplam gelirlerin toplam giderleri karşılama oranı \%68.1'dir. Analiz sonucunda sadece Akkuş, Ardanuç, Artvin ve Mesudiye DOI'leri etkin çıkmıștır. Arhavi, Pazar, Rize, Sürmene, Ş.Karahisar, Trabzon ve Yusufeli DOİ'nin özellikle girdi miktarlarındaki hedef değerleri ve değişim oranları dikkat edilesi gerekmektedir. $\mathrm{Bu}$ DOI'lerin çıktı değişkenlerinin büyük oranlarda azaltılması gerekmektedir. Çıktı değişkenlerine bakıldığında Trabzon DOİ haricindeki tüm DOI'’in gelirleri yeterli gözükmektedir. Sürmene DOİ'nin etkin olabilesi için üretim ve satış miktarlarını iki katına çıkarması gerekmektedir.

IV. durumda çalışma bölgesindeki DOİ'lerin sahip olduğu ormanların karbon tutma, ekoturizm ve rekreasyon, hidrolojik ve erzonyon önleme fonksiyonlarının ekonomik değerleri hesap edilerek çıkt1 değişkenlerinden toplam gelirlere eklenmiştir. Hesaplanan fonksiyon değerleri gelirler üzerinde \% 79.1'lik artış sağlamıştır. Fonksiyon bedelleri sirasiyla en yüksek Artvin, Torul ve Giresun DOI'lerin de, en düşük ise Ünye, Pazar ve Şavşat DOI'lerin de hesaplanmıştır. IV. durumda toplam gelirlerin toplam giderleri karş1lama oran1 \% 130'dur. IV. durumda, III. duruma ek olarak Sürmene ve Yusufeli DOI'leri etkin çıkmıștır. Pazar ve Rize DOİlerinin çıktı değişkenleri olan üretim ve satış rakamlarındaki hedef değerleri ve değişim oranları dikkat edilmesi gerekmektedir. $\mathrm{Bu}$ değerler göz önüne alındığında 2 DOİ'nin de faaliyetlerine işletme müdürlüğü seviyesinde devam etmemesi gerektiği görülmektedir.

Çalışmada analiz sonuçları (tüm durumlar) topluca değerlendirildiğinde, Akkuş, Ardanuç, Artvin ve Mesudiye DOI'leri her durumda etkin çıkmıştır. En yüksek etkinlik değeri dördüncü durumda elde edilmiştir. Trabzon OBM bünyesinde faaliyet gösteren 
DOI'lerden sadece biri (Sürmene DOİ) bir kez etkin çıkmıştır. En çok Artvin OBM bünyesindeki DOİ'ler etkin çıkmıştır. VZA sonucunda, başarısız olan işletmelerin uygulamada girdi olarak kullanılan alan, servet, personel sayıs1, bölge nüfusu ve giderlerini I. durumda \%49.9, II. durumda $\% 57.2$, III. durumda $\% 63.6$ ve IV. durumda ise $\% 55.8$ oranında azaltması gerekmektedir. Analizde kullanılan çıktı değişkenlerinin I. durumda \%97.6, II. durumda \%17.5, III. durumda \%19.7 ve IV. durumda ise \%43.1 oranında arttırması gerekmektedir. Girdi değişkenlerine ilișkin elde edilen değerler Şafak (2009) çalışmasındaki klasik VZA sonuçlarına benzerlik göstermektedir.

Türkiye'de DOİ'lerin etkinlik düzeylerinin belirlenmesine yönelik yeterli sayıda çalışma bulunmamaktadır. Mevcut çalışmalarda genellikle DOİ'lerin ekonomik fonksiyonları üzerinde durulmuştur. Ancak etkinlik düzeylerinin belirlenmesine yönelik çalışmalarda DOİ'lerin sahip oldukları bir takım özelliklere dikkat edilmesi gerekmektedir. Aslında DOİ'ler ekonomik fonksiyonlar yanında ekolojik ve sosyal fonksiyonlara da sahiptir (İlter ve Ok, 2007). $\mathrm{Bu}$ fonksiyonlar DOİ'ler de genellikle gelir kaybına neden olmaktadır. Bu sebepten dolay 1 DOİ'lerin ekonomik katkılarının yanında özellikle yerine getirmiş olduğu ekolojik ve sosyal fonksiyonlarını ekonomik boyutlarının değerlendirilmesi ve işletmelerin etkinlik düzeylerinin belirlenmesinde bu durumunda göz önünde bulundurulması gerekmektedir.

Dikkat edilmesi gereken bir diğer konu da sürdürülebilirlik ilkesi kapsamında DOI'lerin varlıklarının devam ettirebilmesidir. DOI'ler ancak sahip oldukları üretim araçlarını daha etkili kullanmaları durumunda devamlılıklarını sağlayabilecek gelirleri elde edecektir. Ekonomik ölçütlere dayanmadan ve ekonomik analizler yapılmadan siyasi kararlar neticesinde açılan DOI'nin etkin olabilmeleri ve devamlliklarını sağlayabilmeleri için karar vericilerin politik baskilar altında olsa dahi objektif karar vermeleri gerekmektedir. Türkiye'de DOI'lere kanunlarca yüklenmiş olan sosyal amaçlar çoğu zaman ulaşmaları gereken ekonomik amaçların önüne geçmektedir. Özellikle DOİ'nin etkinlik düzeylerinin belirlenmesinde bu durumun da göz önünde bulundurulmas1 gerekmektedir. Etkin çımayan DOI'lerin etkin olabilmeleri için ulaşmaları gereken hedef değerleri incelendiğinde özellikle Trabzon OBM bünyesinde faaliyet gösteren DOI'ler de ki odun üretim miktarının arttırılmas1 gerekmektedir. Doğu Karadeniz Bölgesinde faaliyet gösteren 21 DOİ'nin ortalama sabit maliyetlerinin yüksek olmasında personel giderlerinin payı oldukça yüksektir. $\mathrm{Bu}$ maliyetlerin düşürülmesi için personel politikaları gözden geçirilerek sahip olunan teknik ve idari personelin daha etkin ve verimli çalışılması sağlanmalıdır. Bölgede, özellikle Artvin OBM bünyesinde verilen kanuni haklar oldukça yüksek miktarlarda olup ekonomik amaçlara ulaşmak açısından bu miktarların azaltılmasına yönelik çalışmaların yapılması gerekmektedir. Çalışmada, en yüksek Arazi Tahsis Bedelleri Trabzon OBM bünyesinde hesaplanmıştır. Ancak, Giresun OBM dışında OBM'ler de, Arazi Tahsis Bedellerine ilişskin oluşturulmuş bir veri tabanına rastlanılmamıştır. İzin İrtifak Daire Başkanlığı bünyesinde var olan paket programın yetersiz kaldığ 1 göz önünde bulundurularak, Arazi Tahsis Bedellerine ilişskin DOİler düzeyinde veri tabanı oluşturulmalıdır.

\section{Kaynaklar}

Ateş S.A., Ateş M. 2015. Sosyo-Ekolojik Dönüşüm Karşısında Türkiye: Bir Alternatif Olarak Yeşil Büyüme. Siyaset, Ekonomi ve Yönetim Araştırmaları Dergisi, 3 (4), 69-94.

Ardıç M., Öztürk A., Kayacan B. 2009. Devlet Orman İşletmelerinde Modern Maliyet Yönetimi Yaklaşımlarına İlişkin Değerlendirmeler, II. Ormanc1lıkta Sosyo-Ekonomik Sorunlar Kongresi (19-21 Şubat), Isparta, 272-283.

Asan Ü., Destan S., Özkan U.Y. 2002. İstanbul Korularının Karbon Depolama, Oksijen Üretimi ve Toz Tutma Kapasitesinin Kestirilmesi, Orman Amenajmanında Kavramsal Açılımlar ve Yeni Hedefler Sempozyumu (18-19 Nisan), İstanbul, 194-202.

Baș İ.M., Artar A. 1991. İșletmelerde Verimlilik Denetimi Ölçme ve Değerlendirme Modelleri, MPM Yayınları, Yayın No: 435, Ankara.

Bayramoğlu M.M. 2013. Devlet Orman İşletmelerinin Başari Düzeylerinin Ölçülmesi Ve Optimal İşletme Büyüklüğünün Belirlenmesi 
(Doğu Karadeniz Bölgesi Örneği), Doktora Tezi, KTÜ Fen Bilimleri Enstitüsü, 172 s. Trabzon.

Charnes A., Cooper W.W., Li S. 1989. Using Data Envelopment Analysis to Evaluate Efficiency in the Economic Performance Chinese Cities. Socio-Economic Planning Sciences, 23 (6) 325344.

Ertuğrul İ., Tuş Işık A. 2008. İşletmelerin VZA ile Mali Tablolarına Dayalı Etkinlik Ölçümü: Metal Ana Sanayiinde Bir Uygulama, Afyon Kocatepe Üniversitesi, İ.İ.B.F. Dergisi, 10 (1), 201-217.

Gülcü A., Coşkun A., Yeşilyurt C., Coşkun S., Esener T. 2004. Cumhuriyet Üniversitesi Diş Hekimliği Fakültesi'nin Veri Zarflama Analizi Yöntemiyle Göreceli Etkinlik Analizi, Cumhuriyet Üniversitesi İktisadi ve İdari Bilimler Dergisi, 5 (2), 87-104.

Güngör E., Ayhan A.B. 2016. Bartın Yöresi Orman Kaynaklarının Bal Üretim Potansiyeli ve Ekonomik Değeri. Türkiye Ormancılık Dergisi, 17(1), 108-116

İlter E., Ok K. 2007. Ormancilik ve Orman Endüstrisinde Pazarlama İlkeleri ve Yönetimi, Form Ofset Matbaacilık, Ankara, 476 s.

Kaya G. 2002. Pazarı Olmayan Ürünler Çerçevesinde Orman Kaynaklarının Değerinin Belirlenmesi. Doktora Tezi. İstanbul Üniversitesi Fen Bilimleri Enstitüsü, 290 s. İstanbul.

Güngör E. 2010. Orman Kaynaklarının Bütünleşik İşlevsel Yönetim Planlaması. Doktora Tezi. Bartın Üniversitesi Fen Bilimleri Enstitüsü, 330 s. Bartın.

Orman Genel Müdürlüğü, 2007. 2007 Y1l Kurumsal Mali Durum ve Beklentiler Raporu, Strateji geliştirme Dairesi Başkanlığı, $10 \mathrm{~s}$. Ankara.

Orman Genel Müdürlüğü, 2008. 2008 Y1lı Kurumsal Mali Durum ve Beklentiler Raporu, Strateji geliştirme Dairesi Başkanlığı, 14 s. Ankara.

Orman Genel Müdürlüğü, 2009. 2009 Y1lı Kurumsal Mali Durum ve Beklentiler Raporu, Strateji geliştirme Dairesi Başkanlığı, $17 \mathrm{~s}$. Ankara.

Orman Genel Müdürlüğü, 2010a. Ormancilık İstatistikleri, Türkiye İstatistik Kurumu Matbaası, 84 s. Ankara.

Orman Genel Müdürlüğü, 2010b. 2010 Y1l Kurumsal Mali Durum ve Beklentiler Raporu, Strateji geliştirme Dairesi Başkanlığı, 23 s. Ankara.

Orman Genel Müdürlüğü, 2011. 2011 Y1lı Kurumsal Mali Durum ve Beklentiler Raporu, Strateji geliştirme Dairesi Başkanlığı, 23 s. Ankara.

Orman Genel Müdürlüğü, 2012. Türkiye Orman Varlığı, Orman İdaresi ve Planlama Dairesi
Başkanlığı Yayın No: 85. Envanter Serisi No: 12, 23 s. Ankara.

Şafak İ. 2009. Ege Bölgesi Orman İşletmelerinin Etkinlik Düzeylerinin Değerlendirilmesi, Doktora Tezi, Celal Bayar Üniversitesi Sosyal Bilimler Enstitüsü, 504 s. Isparta.

Yazıc1 K. 1989. Orman İşletmelerinin Ekonomik Büyüklüğü (Doğu Karadeniz Örneği). KTÜ Orman Fakültesi Ders Teksirleri Serisi No:27, 111 s. Trabzon. 